\title{
Analysis of the correlation between malocclusion, bad oral habits, and the caries rate in adolescents
}

\author{
Zhonghua Wang, Jianmei Feng, Qin Wang, Yongchao Yang, Jinping Xiao \\ Department of Stomatology, The First Affiliated Hospital of Hebei North University, Zhangjiakou, China \\ Contributions: (I) Conception and design: Z Wang, J Feng; (II) Administrative support: Q Wang; (III) Provision of study materials or patients: Z \\ Wang, J Feng, Q Wang, Y Yang; (IV) Collection and assembly of data: All authors; (V) Data analysis and interpretation: Z Wang, Y Yang, J Xiao; (VI) \\ Manuscript writing: All authors; (VII) Final approval of manuscript: All authors. \\ Correspondence to: Zhonghua Wang. No.12, Changqing Road, Qiaoxi District, Zhangjiakou, China. Email: wangzhonghua198742@163.com.
}

\begin{abstract}
Background: Malocclusion deformity and caries are common oral diseases in adolescents. In order to explore the correlation between malocclusion deformity and caries prevalence in adolescents, this study analyzed the influence of factors such as poor oral habits on caries in adolescents.

Methods: In this study, 1,093 adolescents aged 11 to 14 enrolled in 2-3 schools in Zhangjiakou area from September 2020 to June 2021 were selected as the research subjects. The basic data of these adolescents were collected by questionnaires. Malocclusion and caries were examined by on-site inspection. Their bad oral habits were also investigated. After data collection, the chi-square test, logistic regression, the MannWhitney $\mathrm{U}$ test, and the Kruskal-Wallis $\mathrm{H}$ test were used for multivariate analysis.

Results: The results showed that the incidence of malocclusion was $72.66 \%$ and the caries rate was $68.8 \%$ among adolescents aged 11-14 in this area. The 4 bad oral habits of biting, mandibular protrusion, lateral chewing, and mouth breathing were the influencing factors of malocclusion in adolescents. Bad oral habits, malocclusion, and frequent consumption of sugary beverages were independent risk factors for caries in adolescents, and significantly positively correlated with the caries rate.
\end{abstract}

Conclusions: Malocclusion and the four bad oral habits were independent risk factors of caries in adolescents.

Keywords: Adolescent caries; malocclusion deformity; bad oral habits; oral health; data analysis

Submitted Oct 27, 2021. Accepted for publication Dec 14, 2021.

doi: $10.21037 / \mathrm{tp}-21-531$

View this article at: https://dx.doi.org/10.21037/tp-21-531

\section{Introduction}

With the spread of health education and improvement of living standards, oral health attracts more attention. Oral diseases, like other organ diseases, have a serious impact on the physiology and psychology of patients (1). Dental caries, or tooth decay, is a common oral disease caused by oral bacteria. The pathogenic factors include dental plaques, bacteria, and the oral environment (2). Caries is an endogenous disease caused by the imbalance of the oral flora. It is mainly formed by the oral flora decomposing the mineral components in the tooth enamel, causing different degrees of damage to the hard tissues of the teeth.
In addition to oral pain or tooth loss, severe lesions may even cause a series of serious complications such as dental pulp disease and periapical disease $(3,4)$. Adolescents are the focus of caries prevention.

Oral cavity is the second largest microbial gathering place of the body, and the health and stability of the abundance of various microorganisms in the oral cavity is very important to balance the relationship between health and disease in the body and the system (5). The microbiome in the normal oral cavity can include a variety of microorganisms such as bacteria, archaea, fungi, protozoa, and viruses. Each kind of microorganism has a specific role, and between the species of microorganisms, 
and between the microorganisms and the host can interact to maintain the stability and health of the body. When the homeostasis of the oral microbiome is broken for some reason, it will cause the unhealthy growth of some strains, which will cause oral diseases, such as periodontitis and gingivitis, and even oral cancer (6). Dental caries is one of the typical oral diseases caused by the unbalanced growth of oral microorganisms. Some scholars believe that bacteria are a prerequisite for the occurrence of dental caries. Some bacteria, such as Streptococcus, produce biofilms during the growth process, which are rich in polysaccharides, making them highly adhesive. Other kinds of cariogenic bacteria adsorb on the surface of the membrane to form dental plaque, which is also the first step in the formation of dental caries (7). In addition, poor oral hygiene habits, education, living standards, and orthodontics may also be risk factors for caries $(8,9)$. A longitudinal cohort study by Warren et al. (10) found that educational attainment, brushing frequency, household water fluoride concentrations, and $100 \%$ juice consumption were associated with the high incidence of dental caries in adolescents and the influence of the mother on the adolescent. Hu et al. [2018] (11) found that women, an older age, high glucose intake, and poor oral health care were risk factors for caries through a multi-stage, stratified, randomized cross-sectional study. Another cross-sectional study by Giugliano et al. [2018] (12) found that parental education and posterior crossbite were associated with dental caries, but dietary habits and frequency of oral cleaning were not significantly associated with dental caries. Malocclusion refers to deformities of teeth, jaws, and faces arising from congenital genetic factors and acquired environmental factors. Patients mainly show individual tooth dislocation, abnormal dental arch morphology, and abnormal tooth arrangement $(13,14)$. Malocclusion deformity has a significant influence on the body and psychology of patients. Except for affecting the maxillofacial development of young children, it also affects oral health, oral function, and appearance, and the influence will become more obvious with the age (15). Clinical studies have found that there is a certain correlation between caries and malocclusion, and some special malocclusions have a high correlation with the caries rate (16). However, there is no unified clinical research to prove that malocclusion is an independent risk factor for caries, and there are few domestic research reports on whether untreated malocclusion will affect the oral health-related quality of life of adolescents. Therefore, from the perspective of adolescents, this study explored the correlation and specific relationship between malocclusion and dental caries through online questionnaires and offline surveys. In order to eliminate the causes of bad habits early, and get rid of the bad habits that have been formed as soon as possible, it will play an important role in effectively preventing the occurrence and development of adolescent caries.

Adolescents aged 11-14 are in the peak period of growth and development. During the peak period of growth and development, a series of significant changes occur in human bones and muscles. At the same time, the orthodontic community generally believes that the best treatment age for orthodontic treatment is still 11-14 years old. Most of the objects receiving orthodontics are still children and adolescents in the rapid growth and development period, which is the third fast growth and development period. In this period, the jaws and alveolar bone are in the active period of growth and reconstruction, with considerable growth potential, and the teeth move faster. Choosing this age group for orthodontic treatment can not only move the teeth quickly, but also induce jaw development. The orthodontic treatment time is shorter, the effect is better, and the effect can be doubled with half the effort. Therefore, understanding the characteristics and trends of the growth and development of adolescents aged 11-14 can take advantage of the situation and actively prevent and treat malocclusion deformities, which is conducive to achieving good treatment results. Therefore, this study used questionnaires for adolescents aged 11-14, collected a large number of samples, and then carried out a diverse scientific statistical analysis of the survey data to study the correlation between malocclusion, malocclusion, bad oral habits and caries. The objective of this study was to provide a basis for prevention and decision-making for the prevention of dental caries and oral health of the entire population, and to provide clinical data support for the public health and health of the entire society. We present the following article in accordance with the SURGE reporting checklist (available at https://dx.doi.org/10.21037/tp-21-531).

\section{Methods}

\section{Research subjects}

In this study, adolescents enrolled in 2-3 schools in District Bridge West from September 2020 to June 2021 were selected. The drinking water source of all the respondents was the water supply in the urban area. A total of 1,200 questionnaires were distributed through 

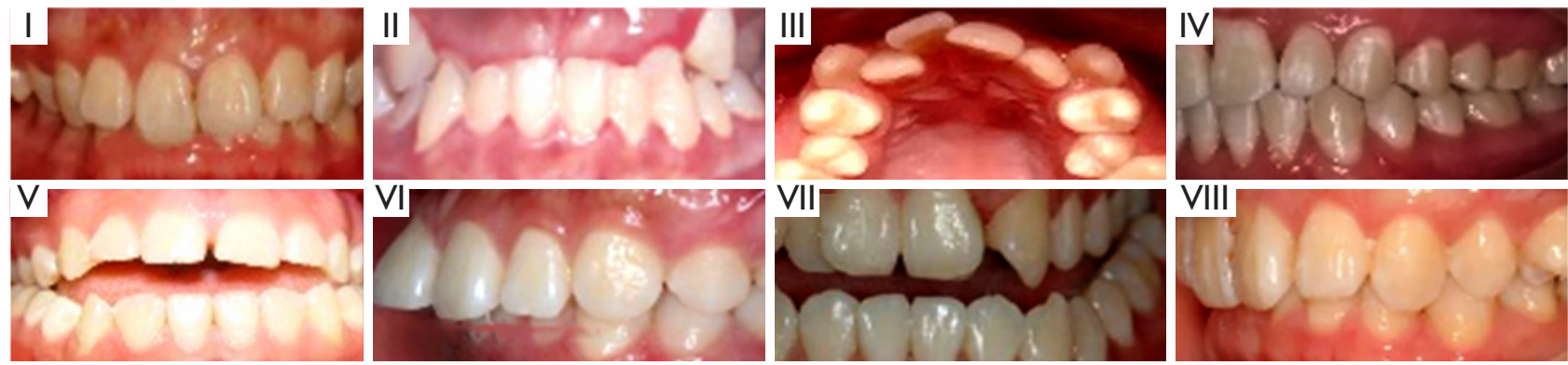

Figure 1 The indications of different types of malocclusion deformity. (I) Deep overbite; (II) anterior crossbite; (III) crowded dentition; (IV) closure of incisors; (V) open bite; (VI) deep coverage; (VII) posterior crossbite; (VIII) clavicular occlusion.

WeChat to investigate bad oral habits and genetic factors, among others. The method of field investigation was used to study malocclusion deformity and caries. All the respondents were voluntarily surveyed. After that, the data of the questionnaires were collected for sorting. The effective response rate of the questionnaire was greater than $90 \%$, which indicated that the quality of the questionnaire survey is good. The bad oral habits stipulated in this study included tongue habits, lip habits, biting objects, mandibular extension, side chewing, and mouth breathing.

\section{Inclusion and exclusion criteria}

The inclusion criteria were as follows: (I) the subjects were aged between 11 and 14 years old, and subjects were Han with unlimited gender; (II) the subjects had no physical disability; and (III) the subjects had no systemic diseases.

The exclusion criteria were as follows: (I) the subjects were currently undergoing or previously underwent orthodontic treatment; (II) the questionnaire was not complete, or subjects could not cooperate with the doctor to complete the examination; and (III) the subject withdrew during the experiment.

The study was approved by The First Affiliated Hospital of Hebei North University (No. K2020266). All participants and their families were aware of the study and signed the informed consent forms, and the study was conducted in accordance with the Declaration of Helsinki (as revised in 2013).

\section{Examination method of malocclusion deformity and caries}

Both malocclusion deformity and caries were examined on site. Angle classification was used for the diagnosis of malocclusion deformity. The investigated subjects were observed for types of malocclusion deformity and the molar relationships (neutral, far, near). When the subjects met any of the following indicators, they were determined as having malocclusion deformity, including: (I) deep overbite; (II) anterior crossbite; (III) crowded dentition; (IV) closure of incisors; (V) open bite; (VI) deep coverage; (VII) posterior crossbite; and (VIII) clavicular occlusion. Caries was determined according to the criteria of the fourth edition of Oral Health Survey Method issued by the National Health and Family Planning Commission. Caries was determined when the subjects met any of the following indicators: (I) there were obvious cavities or enamel damage in the gap or smooth surface of teeth; (II) there were obvious lesions that could be detected to soften the bottom or wall of the cave; (III) there was a filling in the tooth; (IV) the tooth had been filled with caries; (V) lack of caries (Figure 1).

\section{Quality control}

After data collection, it was grouped by 2 doctors with significant clinical experience. Adolescents with a similar economic level, parent education level, and ethnic background were compared for the caries deficiency index and dental aesthetic index (17), according to which all the subjects were divided into 4 groups: group A with caries and malocclusion; group B with caries but no malocclusion; group $\mathrm{C}$ with malocclusion no dental caries; and group $\mathrm{D}$ without dental caries or malocclusion. The effect of malocclusion on the incidence of caries was analyzed, and the severity of caries was studied in the group A with different types of malocclusions. Variable factors such as the diet and health habits of the subjects were remotely monitored by WeChat, and the diet, health habits, and other caries-related factors were recorded. 


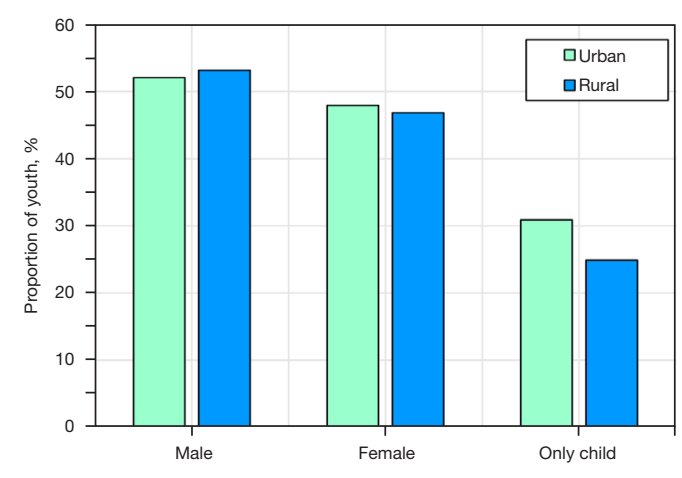

Figure 2 General information of the research subjects.

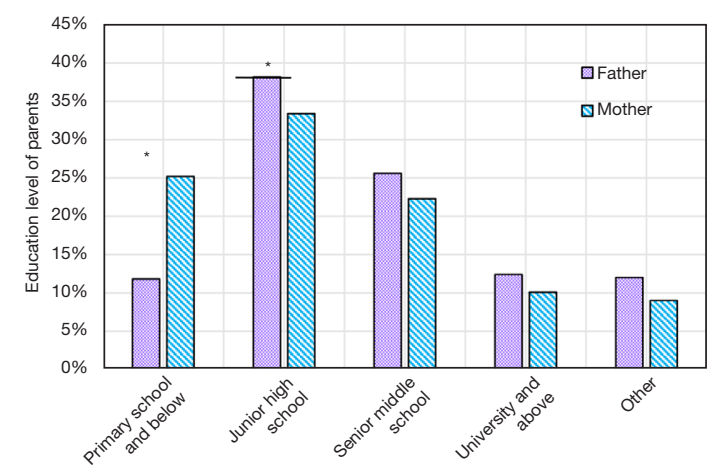

Figure 3 Parents' education level of the research subjects. * indicates that the difference is statistically significant.

\section{Statistical analysis}

The data of this study were collated by Excel 2019 and analyzed by SPSS 19.0 software. The Mann-Whitney U test was used for rank sum testing of two independent samples. The Kruskal-Wallis $\mathrm{H}$ test was used for comparisons of multiple samples. The correlation between 2 or more variables was tested by the $\chi^{2}$ test. The test level $\alpha=0.05$ and $\mathrm{P}<0.05$ indicated that the difference was statistically significant.

\section{Results}

\section{General information of the research subjects}

In this study, 1,200 questionnaires were randomly distributed to adolescents in 3 schools, and 1,138 questionnaires were recovered, of which 1,093 were valid. Thus, the effective recovery rate was $96.05 \%$. This study included 1,093 adolescents, aged 11-14 years, with an average age of $12.5 \pm 1.3$ years. There were 651 urban residents, including 339 males, 312 females. Of them, 201 were children. There were 442 rural residents, including 235 males, 207 females. Of them, 110 were children, as shown in Figure 2.

The study of parents' educational level found that fathers' educational level was mainly junior and senior high school (63.8\%) and mothers' educational level was mainly junior high and below (58.9\%), as shown in Figure 3.

\section{Examination of malocclusion and caries in adolescents}

Among the 1,093 adolescents, 572 had carries, including 305 males and 267 females, and the caries rate was $52.33 \%$. A total of 793 cases of malocclusion were detected, including 387 males and 406 females, with a prevalence rate of $72.55 \%$. According to the composition of malocclusion, subjects were divided into 250 cases of angle class I (31.53\%), 130 cases of angle class II (16.39\%), 96 cases of angle class II $(12.11 \%)$, and 167 cases of angle class III $(21.06 \%)$, as shown in Figure 4.

\section{Correlation between bad oral habits, anterior malocclusion, and caries}

The gender, urban and rural registrations, parents' educational level, and oral habits of adolescents were analyzed, with anterior malocclusion as the independent variable and caries as the dependent variable in the chisquare test, as shown in Table 1. The results showed that parents' educational level, bad oral habits, tooth trauma, malocclusion, and frequent sugary drinks were risk factors for caries in adolescents. The probability of caries in adolescents with poor oral habits, tooth trauma, malocclusion, and frequent sugary drinks was higher. In addition, parents' educational level may have an impact on caries in adolescents.

The caries of adolescents was taken as the dependent variable, and the related factors with significant differences $(\mathrm{P}<0.05)$ in the chi-square test were selected as independent variables for the multivariate logistic regression analysis on caries (Figure 5, Table 2). The results showed that bad oral habits, malocclusion, and frequent consumption of sugary drinks were important influencing factors for caries in adolescents. 

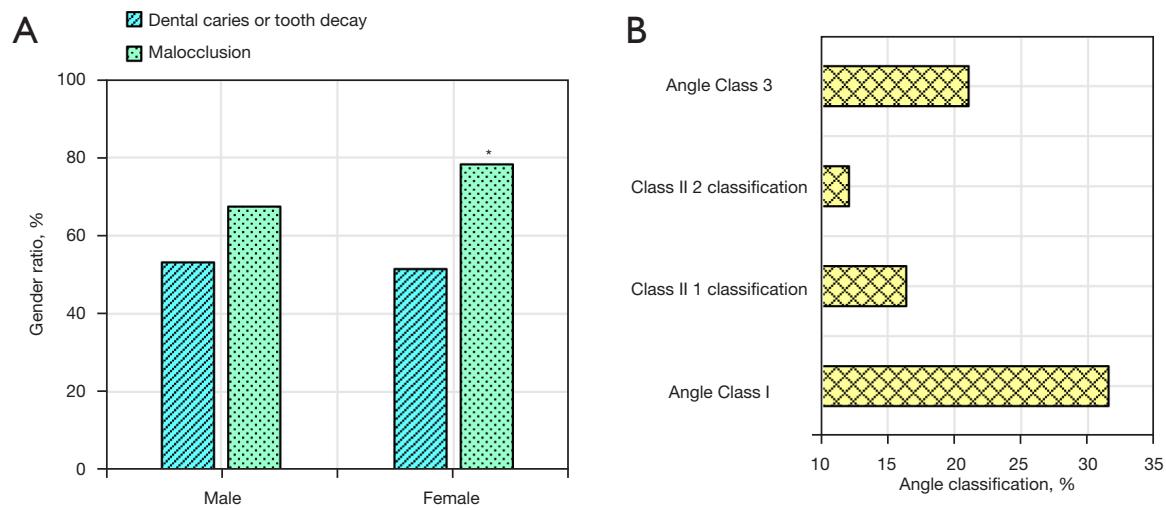

Figure 4 Results of malocclusion and caries examination in adolescents. (A) Incidence of malocclusion and caries in different genders. (B) Angle classification results of malocclusion in adolescents. ${ }^{*}$ indicates that the difference is statistically significant.

Table 1 Chi-square test results of caries in adolescents aged 11-14 years

\begin{tabular}{|c|c|c|c|c|c|c|c|}
\hline Factors & Group & \multicolumn{2}{|c|}{ Dental caries } & \multicolumn{2}{|c|}{ Non-dental caries } & $\chi^{2}$ & $\mathrm{P}$ \\
\hline \multirow[t]{2}{*}{ Gender } & Male & 305 & 53.1 & 269 & 46.9 & 1.135 & 0.223 \\
\hline & Female & 267 & 51.4 & 252 & 48.6 & & \\
\hline Only child & - & 144 & 46.3 & 167 & 53.7 & 2.351 & 0.081 \\
\hline Inhabitancy & Rural & 208 & 47.1 & 234 & 52.9 & & \\
\hline \multirow[t]{2}{*}{ Standard of culture } & Father & 438 & 40.1 & 655 & 59.9 & 4.127 & 0.038 \\
\hline & Mother & 611 & 55.9 & 482 & 44.1 & & \\
\hline Bad oral habits & Existence & 386 & 75.4 & 126 & 24.6 & 18.125 & 0.000 \\
\hline Malocclusion deformity & - & 485 & 61.2 & 308 & 38.8 & 11.447 & 0.005 \\
\hline Dessert often consumed & - & 278 & 51.7 & 260 & 48.3 & 1.877 & 0.132 \\
\hline $\begin{array}{l}\text { Frequent consumption of } \\
\text { sugary drinks }\end{array}$ & - & 349 & 56.2 & 272 & 43.8 & 6.449 & 0.017 \\
\hline
\end{tabular}

\section{Relationship between different risk factors and caries in adolescents}

The data in this study did not conform to the normal distribution. After grouping of the patients, the MannWhitney $\mathrm{U}$ test was used to analyze the overall difference between malocclusion and caries, and the heterogeneity was calculated. The results are shown in Table 3. The results showed that the average rank of malocclusion in adolescents with caries was 23.15 , and the average rank of malocclusion in non-caries adolescents was 12.83 . The results of the Mann-Whitney $\mathrm{U}$ test showed that there were significant differences in the incidence of malocclusion and the distribution of bad oral habits between caries adolescents and non-caries adolescents $(\mathrm{P}<0.05)$.

\section{Relationship between bad oral habits, malocclusion, and} caries prevalence in adolescents

According to whether the subjects had caries and 
malocclusion, 1,093 adolescents were divided into 4 groups, including 485 cases of caries and malocclusion in group A, 87 cases with caries but no malocclusion in group B, 308 cases with caries but no malocclusion in group C, and 213 cases with caries and no malocclusion in group D. Oral habits included tongue habits, lip habits, biting, mandibular extension, lateral chewing, and mouth breathing, among others. Among 512 adolescents, 64 cases had tongue habits, 109 cases had lip habits, 63 cases exhibited biting, 45 cases had mandibular extension, 155 cases exhibited lateral chewing, and 76 cases exhibited mouth breathing. The grouping information and bad oral habits are shown in Figure 6.

The relationship between bad oral habits and caries was analyzed (Figure 7). The results showed that among the

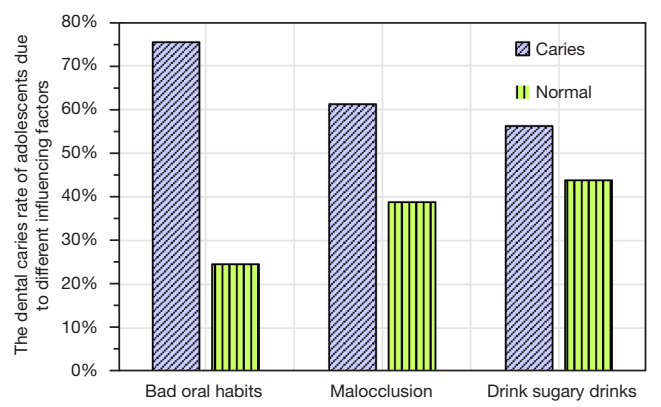

Figure 5 Comparison of caries prevalence among adolescents with different influencing factors. adolescents with caries, there were 21 cases with tongue habits, accounting for $3.67 \%, 48$ cases of lip sucking habit, accounting for $8.39 \%, 23$ cases of biting, accounting for $4.02 \%, 22$ cases of mandibular protrusion, accounting for $3.85 \%, 73$ cases of unilateral chewing, accounting for $12.76 \%, 32$ cases of oral respiration, accounting for $5.59 \%$, 122 adolescents with 2 kinds of bad habits, accounting for $21.33 \%$, and 45 adolescents with 3 or more bad habits, accounting for $7.87 \%$. Lip habits and unilateral chewing occurred in most cases of caries.

The relationship between bad oral habits and malocclusion was analyzed (Figure 8). The results showed that there were 34 cases of tongue habits, accounting for $3.91 \%, 59$ cases of lip sucking habit, accounting for $7.44 \%, 39$ cases of biting, accounting for $4.92 \%, 27$ cases of mandibular protrusion, accounting for $3.40 \%, 96$ cases of partial chewing, accounting for $12.11 \%, 45$ cases of oral respiration, accounting for $5.67 \%, 165$ adolescents with 2 kinds of bad habits, accounting for $80.81 \%$, and 68 adolescents with 3 or more bad habits, accounting for $8.58 \%$. Adolescents who exhibited biting, mandibular advancement, lateral chewing, and mouth breathing had a higher probability of malocclusion, and the difference was statistically significant $(\mathrm{P}<0.05)$.

\section{Discussion}

Caries is a common chronic infectious disease in the oral

Table 2 Logistic regression analysis results of caries in adolescents aged 11-14 years

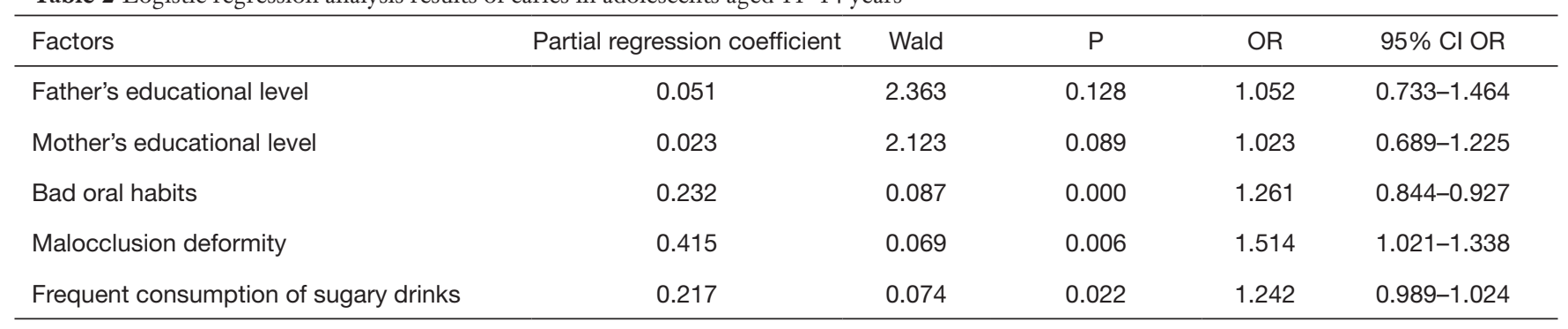

OR, odds ratio; $\mathrm{Cl}$, confidence interval.

Table 3 Mann-Whitney $U$ test results of whether adolescents have caries

\begin{tabular}{llll}
\hline Original hypothesis & Test & $P$ & Decision maker \\
\hline Distribution of malocclusion is the same in caries categories & Mann-Whitney U & 0.015 & Reject original assumptions \\
The distribution of poor oral habits is the same in caries categories & Mann-Whitney U & 0.011 Reject original assumptions \\
The distribution of sugary drink intakes is the same in caries categories & Mann-Whitney U & 0.023 Reject original assumptions \\
\hline
\end{tabular}


A

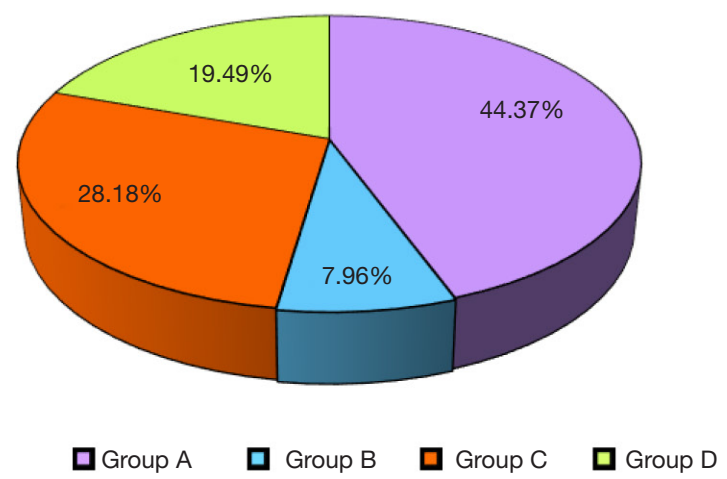

B

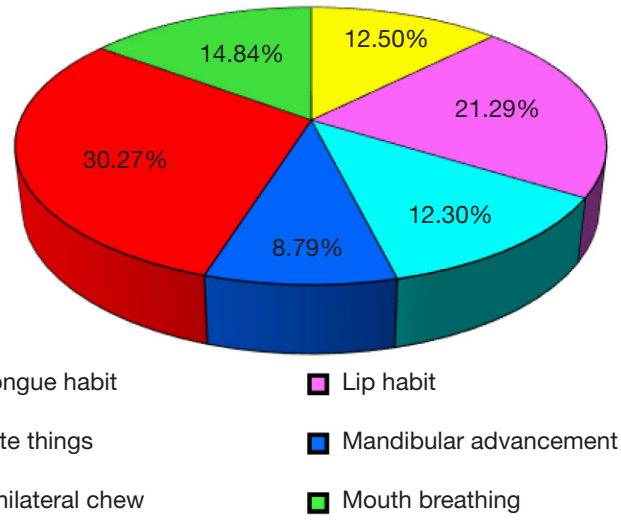

Figure 6 The grouping information and data on the bad oral habits of the research subjects. (A) The grouping information. (B) The proportion of bad oral habits.

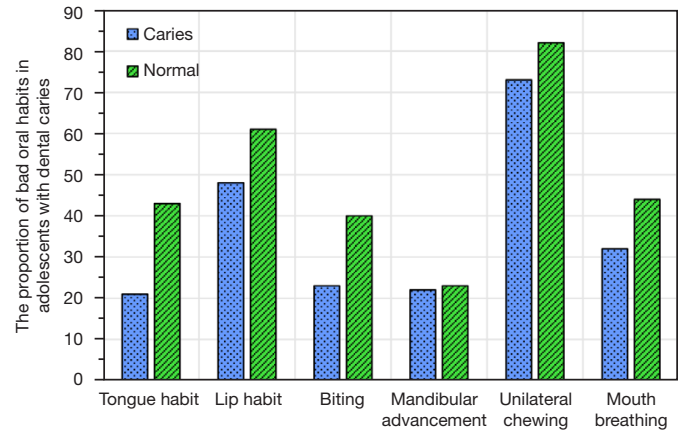

Figure 7 Relationship between bad oral habits and the incidence of dental caries in adolescents.

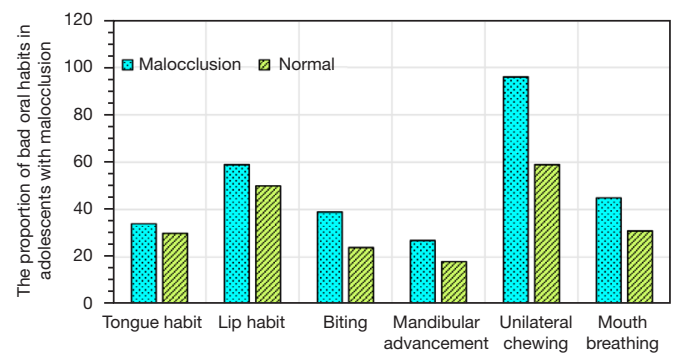

Figure 8 Relationship between bad oral habits and the incidence of malocclusion in adolescents.

cavity, which is generally caused by endogenous bacterial infections. It can be said that microbial participation is the only reason for caries. Caries are caused by many factors, including bacteria, dental plaques, diet, and oral environment (18). Caries are usually accompanied by pathological changes of dental hard tissue. The enamel and dentine of patients are usually characterized by mineral demineralization and organic decomposition. Clinically, changes in the shape and color of dental hard tissue can be observed (19). At the early stage of caries, the transparency of the teeth decreases, the enamel is chalky, the hard tissue of the lesion is demineralized, the pigment precipitates, and the local color is yellowish brown. With the progression of the disease, the enamel and dentin loosen and soften, and finally develop into caries cavities (20). There are three theories regarding the etiology of dental caries, namely chemical bacteriology, protein dissolution theory, and protein dissolution-chelation theory. Chemical bacteriology posits that bacteria on the tooth surface interact with carbohydrates in the oral cavity to generate acids and the demineralization of inorganic substances in the dental hard tissue, and proteolytic enzymes in the oral cavity dissolve organic matter to cause tooth defects. Proteolysis theory suggests that proteolytic enzymes in the oral cavity first decompose the local organic matter in the tooth, then bacteria invade the tooth channel, and microorganisms invade the tooth through the enamel organic pathway to form caries. Protein dissolution-chelation theory suggests that microbial dissolution of organic substances on the tooth surface releases various chelating agents, which then dissolve hydroxyapatite crystals to produce dental caries $(21,22)$.

The factors leading to caries are still not clear, but they are generally considered to be the combined effect of bacteria, diet, and the host. Malocclusion deformity refers to tooth, jaw, or craniofacial deformity caused by the combined effect of congenital genetic factors and acquired environmental factors (23). Similar to caries, 
malocclusion is also a common oral disease. However, the etiology of malocclusion is complex, and it is related to environmental factors except genetic factors. Whether malocclusion will increase the incidence of caries remains unclear. Due to differences in regions, drinking water, and other conditions, the incidence of caries and the prevalence of malocclusion in different age groups varies. The results of this study showed that the incidence of malocclusion in adolescents aged 11-14 years old in this region was $72.66 \%$, and the caries rate was $68.8 \%$, higher than other regions at home and abroad. Oral habits also affect the development of occlusion. For example, finger sucking can cause anterior open occlusion (24). Therefore, we analyzed the relationship between bad oral habits and the prevalence of malocclusion. The results showed that adolescents who exhibited biting, mandibular protraction, lateral chewing, and mouth breathing had a higher probability of malocclusion than other adolescents $(\mathrm{P}<0.05)$. in terms of the relationship between malocclusion and the prevalence of dental caries, the "quadruple factor theory" suggests that dental caries is determined by 4 factors: bacteria, food, time, and the host. This study found that the prevalence of dental caries in patients with malocclusion was as high as $61.2 \%$. Logistic regression and Mann-Whitney $U$ analysis showed that there was a significant difference between malocclusion and dental caries $(\mathrm{P}<0.05)$. A cross-sectional study by Feldens et al. [2015] (25) also confirmed the above view. The reason might be the accumulation of plaque caused by factors such as dentition accumulation resulting from malocclusion deformity, which makes it difficult to clean. Poor personal oral hygiene eventually leads to caries. Additionally, bad oral habits and frequent consumption of sugar-containing drinks can also lead to caries. The mechanism is similar to that of chemical bacteriology, that is, bad oral habits lead to bacterial accumulation and cause caries. However, gender, region, parents' educational level, and tooth trauma were found to be not significantly correlated with caries. In summary, the results of this study revealed that bite, mandibular extension, lateral chewing, and mouth breathing were the influencing factors of adolescent malocclusion. In addition, poor oral habits, malocclusion, malocclusion, and frequent sugary drinks were independent risk factors leading to dental caries in adolescents; and these above three factors were significantly positively correlated with the caries rate. Therefore, in the subsequent anti-caries work for young people, it can focus on the above factors, so that young people can effectively prevent and eliminate bad habits in the early stage, and block the occurrence of caries.

\section{Conclusions}

This study focused on the relationship between malocclusion, bad oral habits, and caries in adolescents aged 11-14 years, and it showed that the incidence of malocclusion and caries in adolescents in this region was high. Poor oral habits are associated with malocclusion. Adolescents exhibiting biting, mandibular protrusion, unilateral chewing, and mouth breathing are more likely to have malocclusion. The caries rate was affected by 3 factors: malocclusion, bad oral habits, and frequent consumption of sugary drinks. However, no significant relationship was found between gender, region, parents' educational level, and the caries rate. This study provides clinical guidance for the oral health and hygiene of adolescents in the region, and provides a decision-making basis for caries prevention and the oral health of adolescents. Nevertheless, there are still some shortcomings in this study. The influence of different types of malocclusions on the caries rate of adolescents is not analyzed, which needs to be improved in future work.

\section{Acknowledgments}

Funding: This work was supported by the 2021 Medical Science Research Project Plan of Hebei Provincial Health Commission (No. 20211453).

\section{Footnote}

Reporting Checklist: The authors have completed the SURGE reporting checklist. Available at https://dx.doi. org/10.21037/tp-21-531

Data Sharing Statement: Available at https://dx.doi. org/10.21037/tp-21-531

Conflicts of Interest: All authors have completed the ICMJE uniform disclosure form (available at https://dx.doi. org/10.21037/tp-21-531). The authors have no conflicts of interest to declare.

Ethical Statement: The authors are accountable for all aspects of the work in ensuring that questions related to the accuracy or integrity of any part of the work are appropriately investigated and resolved. The study was approved by The First Affiliated Hospital of Hebei North 
University (No. K2020266). All participants and their families were aware of the study and signed the informed consent forms, and the study was conducted in accordance with the Declaration of Helsinki (as revised in 2013).

Open Access Statement: This is an Open Access article distributed in accordance with the Creative Commons Attribution-NonCommercial-NoDerivs 4.0 International License (CC BY-NC-ND 4.0), which permits the noncommercial replication and distribution of the article with the strict proviso that no changes or edits are made and the original work is properly cited (including links to both the formal publication through the relevant DOI and the license). See: https://creativecommons.org/licenses/by-nc-nd/4.0/.

\section{References}

1. Chaffee BW, Rodrigues PH, Kramer PF, et al. Oral healthrelated quality-of-life scores differ by socioeconomic status and caries experience. Community Dent Oral Epidemiol 2017;45:216-24.

2. Neves ÉTB, Dutra LDC, Gomes MC, et al. The impact of oral health literacy and family cohesion on dental caries in early adolescence. Community Dent Oral Epidemiol 2020;48:232-9.

3. Ziller S, Jordan AR, Oesterreich D. Oral health goals for Germany 2030: reduction of caries and periodontitis and improvement of prevention. Bundesgesundheitsblatt Gesundheitsforschung Gesundheitsschutz 2021;64:821-9.

4. Kragt L, van der Tas JT, Moll HA, et al. Early Caries Predicts Low Oral Health-Related Quality of Life at a Later Age. Caries Res 2016;50:471-9.

5. Kilian M, Chapple IL, Hannig M, et al. The oral microbiome - an update for oral healthcare professionals. Br Dent J 2016;221:657-66.

6. Sampaio-Maia B, Caldas IM, Pereira ML, et al. The Oral Microbiome in Health and Its Implication in Oral and Systemic Diseases. Adv Appl Microbiol 2016;97:171-210.

7. Deng M, Qi X, Xu X, et al. Research progress of human oral microbial metagenomics. West China Journal of Stomatology 2013;31:107-11.

8. Tenelanda-López D, Valdivia-Moral P, Castro-Sánchez M. Eating Habits and Their Relationship to Oral Health. Nutrients 2020;12:2619.

9. Mattos MG, Fernandez CA, Masterson D, et al. Is the caregivers' oral health related to dental caries in children or adolescents? A systematic review. Clin Oral Investig 2019;23:3843-54.
10. Warren JJ, Van Buren JM, Levy SM, et al. Dental caries clusters among adolescents. Community Dent Oral Epidemiol 2017;45:538-44.

11. Hu J, Jiang W, Lin X, et al. Dental Caries Status and Caries Risk Factors in Students Ages 12-14 Years in Zhejiang, China. Med Sci Monit 2018;24:3670-8.

12. Giugliano D, d'Apuzzo F, Majorana A, et al. Influence of occlusal characteristics, food intake and oral hygiene habits on dental caries in adolescents: a cross-sectional study. Eur J Paediatr Dent 2018;19:95-100.

13. Zou J, Meng M, Law CS, et al. Common dental diseases in children and malocclusion. Int J Oral Sci 2018;10:7.

14. Cadenas de Llano-Pérula $M$, Ricse E, Fieuws $S$, et al. Malocclusion, Dental Caries and Oral Health-Related Quality of Life: A Comparison between Adolescent School Children in Urban and Rural Regions in Peru. Int J Environ Res Public Health 2020;17:2038.

15. Kolawole KA, Folayan MO. Association between malocclusion, caries and oral hygiene in children 6 to 12 years old resident in suburban Nigeria. BMC Oral Health 2019;19:262.

16. Martins MT, Sardenberg F, Bendo CB, et al. Dental caries are more likely to impact on children's quality of life than malocclusion or traumatic dental injuries. Eur J Paediatr Dent 2018;19:194-8.

17. Vozza I, Capasso F, Calcagnile F, et al. School-age dental screening: oral health and eating habits. Clin Ter 2019;170:e36-40.

18. Sakaryali D, Bani M, Cinar C, et al. Evaluation of the impact of early childhood caries, traumatic dental injury, and malocclusion on oral health-Related quality of life for Turkish preschool children and families. Niger J Clin Pract 2019;22:817-23.

19. Cirulli N, Cantore S, Ballini A, et al. Prevalence of caries and dental malocclusions in the apulian paediatric population: an epidemiological study. Eur J Paediatr Dent 2019;20:100-4.

20. Militi A, Nucera R, Ciraolo L, et al. Correlation between Caries, Body Mass Index and Occlusion in an Italian Pediatric Patients Sample: A Transverse Observational Study. Int J Environ Res Public Health 2020;17:2994.

21. Martins MT, Sardenberg F, Bendo CB, et al. Dental caries remains as the main oral condition with the greatest impact on children's quality of life. PLoS One 2017;12:e0185365.

22. Arora G, Bhateja S. Prevalence of dental caries, periodontitis, and oral hygiene status among 12-year-old schoolchildren having normal occlusion and malocclusion in Mathura city: a comparative epidemiological study. 
Indian J Dent Res 2015;26:48-52.

23. Singh A, Purohit B, Sequeira P, et al. Malocclusion and orthodontic treatment need measured by the dental aesthetic index and its association with dental caries in Indian schoolchildren. Community Dent Health 2011;28:313-6.

24. Feldens CA, Ardenghi TM, Dos Santos Dullius AI, et al. Clarifying the Impact of Untreated and Treated Dental
Caries on Oral Health-Related Quality of Life among Adolescents. Caries Res 2016;50:414-21.

25. Feldens CA, Dos Santos Dullius AI, Kramer PF, et al. Impact of malocclusion and dentofacial anomalies on the prevalence and severity of dental caries among adolescents. Angle Orthod 2015;85:1027-34.

(English Language Editor: C. Betlazar-Maseh)

Cite this article as: Wang Z, Feng J, Wang Q, Yang Y, Xiao J. Analysis of the correlation between malocclusion, bad oral habits, and the caries rate in adolescents. Transl Pediatr 2021;10(12):3291-3300. doi: 10.21037/tp-21-531 